\title{
KAJIAN DESAIN DINING SET MID CENTURY DENGAN SISTEM KNOCK-DOWN STUDI KASUS NEW ELEGANT, LTD.
}

\author{
Susi Hartanto, Aditya Cipta Sugandha \\ Universitas Pelita Harapan \\ susi.fdtp@uph.edu
}

\begin{abstract}
Abstrak. Mid century merupakan gaya furnitur yang cukup susah dibuat versi knock-down karena strukturnya yang ramping. Namun dengan permintaan pasar yang cukup tinggi akan gaya ini, perusahaan furnitur harus selalu mampu menghasilkan produk dengan gaya yang diminati dan memiliki keunggulan, salah satu keunggulan yang bisa ditawarkan adalah dengan sistem knock-down. Knock-down merupakan sistem bongkar pasang yang umum dipakai agar produk yang dihasilkan ringkas dan hemat tempat. Untuk itu diambil studi kasus pada perusahaan furnitur New Elegant, Ltd., Vietnam. Perusahaan ini lebih fokus pada produk dining set. Desain kursi makan mid century knock-down yang bisa diproduksi New Elegant Ltd., adalah yang memiliki 3 konstruksi dasar sama dengan standar pabrik (seat frame, front legs, chair back). Sedangkan untuk desain meja makan mid century yang bisa diproduksi adalah yang memiliki struktur table top dan table legs yang dikunci dengan hardware (baik dengan atau tanpa apron). Bentuk desain sifatnya relatif, menyesuaikan ciri-ciri desain mid century yang membulat dan ramping. Harga penawaran ke klien harus yang masuk dalam kisaran harga ritel USD90-99 per produk, dan sesuai perhitungan biaya, desain masuk dalam kategori harga yang kompetitif. Secara loadability pun, daya tampung dalam 1 kontainer 40ft HC lebih besar $48 \%$ dibanding set serupa yang tidak knock-down. Dengan demikian, model desain ini bisa menjadi salah satu referensi bagaimana cara modifikasi desain mid century versi knock-down.
\end{abstract}

Kata kunci: mid century, knock-down, dining set

\begin{abstract}
Mid century is one of furniture style which is quite difficult to be made knock-down for its slim structure. With market high demand of this particular style, furniture company needs to always release new designs with added value. One of added values is knock-down system. Knock-down is generally applied in furniture for space saving. A Case study is taken at New Elegant, Ltd., Vietnam, a furniture company focuses more on dining sets. Mid century dining chair design which can be produced at this company should have 3 basic constructions similar to factory standards (seat frame, front legs, chair back). While dining table design should have table top and table legs assembled with hardware (with or without apron). Forms of design is relative, adjusting to mid century design characteristics, rounded and slim. Quotation price should be in retail price rangeof USD90-99 per piece, and according to cost estimation, designs proposed are within this range. In terms of loadibility, knock-down designs in this research are $48 \%$ more efficient in space compared to those with non knock-down structure.Thus, this design model could be a reference on how to modify knock-down mid century designs.
\end{abstract}

Keywords: mid century, knock-down, dining set

\section{Pendahuluan}

\subsection{Latar Belakang/ Fenomena \& Isu}

New Elegant Ltd adalah perusahaan one stop furniture service yang didirikan pada 2014 di Ho Chi Minh, Vietnam. Perusahaan ini menerima pemesanan furnitur mulai dari desain, produksi, quality control, hingga pengiriman dan administrasi ekspor impor furnitur melalui kerjasama pabrik dan trading agent rekanan. Perusahaan memiliki buyer peritel terutama dari US dan Kanada, seperti Avalon, OSP, Homelegance, New Classic, dan sebagainya, dengan portfolio produk yang kebanyakan adalah American dining set, baik itu standar (18"), counter height (24"), ataupun bar height (30"). Perusahaan bermain di area harga ritel murah hingga menengah dengan kisaran USD480 hingga USD550 untuk 1 set meja makan (1 meja 4 kursi). Untuk harga ekonomis, peritel umumnya menjual dalam bentuk knock-down, dimana 
pengguna harus merakit furnitur sendiri. Kelebihan sistem knock-down adalah hemat ukuran packing, sehingga 1 kontainer bisa memuat lebih banyak furnitur. Efeknya, harga bisa ditekan agar lebih murah. Kesulitannya, banyak konstruksi furnitur yang harus dipikirkan agar produk tetap kokoh, mudah diproduksi, mudah dipasang, dan cocok dari sisi harga.

Peritel furnitur selalu membutuhkan desain-desain baru dan terkini agar selalu memiliki daya saing. Kategori gaya yang masih sangat diminati adalah mid century yang cukup banyak dijual oleh semua peritel di US. Untuk itu, perusahaan setiap hari menghasilkan desain-desain baru yang ditawarkan ke buyer atau untuk kebutuhan pameran tahunan, termasuk juga produk bergaya mid century ini. Namun, karena biasanya perusahaan mengembangkan produk American style, gaya ini termasuk yang baru dikembangkan, sehingga membutuhkan pertimbangan yang pas baik itu dari sisi desain, konstruksi knock-down, harga, dan sebagainya. Tidak semua desain mid century cocok untuk produksi masal di pabrik rekanan. Tidak semua desain mid century juga cocok dibuat knock-down karena bisa menghilangkan unsur estetisnya. Untuk itu, artikel ini mengkaji dan mengajukan desain mid century dining set seperti apa yang cocok dan bisa berdaya saing bagi perusahaan New Elegant, Ltd sebagai studi kasus.

\subsection{Literatur}

\subsubsection{Konstruksi Knock-Down Standar Perusahaan}

Knock-down merupakan sistem bongkar pasang yang umum diaplikasikan pada furnitur ritel. Sistem ini berkembang pesat sejak IKEA mempopulerkannya dengan istilah flat pack, membuat furniture menjadi jauh lebih ringkas dan hemat tempat.

Kelebihan furnitur sistem knock-down:

1) Hemat ruang penyimpanan dan pengiriman

2) Harga lebih terjangkau dibandingkan furnitur siap pakai

Kelemahan furnitur sistem knock-down:

1) Desain lebih terbatas karena harus mempertimbangkan kemudahan pasang dan produksi.

2) Kurang tahan lama jika konstruksi atau hardware yang dipakai kurang kuat.

3) Butuh waktu untuk merakit.

Kekurangan no.1 bisa diakali dengan permainan desain. Kekurangan no.2 juga bisa diselesaikan karena SDM perusahaan telah berpengalaman dalam konstruksi dan hardware selama 40 tahun di bidang furnitur. Kekurangan no.3 juga sebenarnya sifatnya relatif karena peritel juga menyediakan jasa pasang jika pengguna malas merakit sendiri. Sehingga tetap knock-down memberikan manfaat yang lebih besar dibanding kekurangannya.

Dari sisi kajian literatur:

Berikut beberapa landasan konsep strategi riset dan pengembangan (R\&D) hasil penelitian pada beberapa perusahaan manufaktur:

\section{Strategi carry over detail}

Carry over detail menurut Warrel (2006) adalah sebuah strategi R\&D dimana elemen desain dari produk sebelumnya dibawa ke produk berikutnya. Menurut Ulrich dan Eppinger (2012), Sanchez (2002) dan Differ (2011), strategi ini sering diterapkan agar perusahaan dapat bersaing cepat di pasar secara ekonomis. Elemen desain ini harus mencerminkan nilai brand perusahaan tersebut. Dengan pengulangan yang konsisten, karakter desain perusahaan dapat dikenali oleh customer. 


\section{Strategi modularitas}

Strategi ini adalah strategi R\&D dalam perusahaan dimana produk dibagi menjadi beberapa modul komponen yang membentuk fungsi produk, sehingga lini produk dapat dibuat variasinya dengan mudah, Andersson dan Warell (2015). Modul komponen dapat berupa komponen elektronik, komponen struktur dan material. Contohnya sebuah kursi memiliki 4 komponen (sandaran, kaki, dudukan, sandaran tangan), dimana masing - masing komponen ada variasi bentuk, material dan ukuran. Variasi desain produk dapat dibuat dengan kombinasi antara komponen - komponen ini. Keuntungan yang didapatkan dari konsep modularitas; penekanan biaya, meningkatkan variasi produk dalam waktu cepat, pengurangan waktu produksi, memudahkan quality control.

\section{Strategi Revitalization \& Redesign}

Kedua strategi ini dapat diambil perusahaan ketika sebuah perusahaan mengalami penurunan dengan harapan bahwa perusahaan akan mampu menaikkan kembali posisi perusahaan di pasar.

- Menurut Keller (2012) Revitilation adalah Strategi R\&D mengeluarkan produk yang benar - benar berbeda dari produk sebelumnya. Keputusan ini umumnya diambil bila perusahaan sudah dalam keadaan mundur dan banyak pesaing. Disini harus dipikirkan benar - benar nilai brand apa yang mau dipertahankan.

- Menurut Kapferer (2014) Redesign adalah strategi R\&D untuk mendesain ulang produk yang sudah ada dengan melakukan perubahan - perubahan kecil, Strategi ini biasanya diambil agar perusahaan tetap dapat mengikuti persaingan pasar.

\section{Strategi Point of Difference (POD) dan Point of Parity (POP)}

Menurut Anderson dan Warell (2013), Point Of Difference adalah strategi R\&D untuk membuat fitur - fitur unik pada produknya yang membedakan produk perusahaan dengan pesaing. Customer dapat langsung mengasosiasikan fitur dengan perusahaan tanpa harus melihat merek. Sebaliknya Point of Parity adalah strategi R\&D dimana perusahaan mengadopsi fitur - fitur pada produk yang mirip dengan perusahaan sejenis.

\section{Strategi Champions, Star \& Lead Products}

Menurut Anderson dan Warell (2015), perusahaan yang memiliki banyak portfolio produk pasti memiliki produk yang diunggulkan, dan inilah yang disebut sebagai champion/star/lead product. Strategi ini dilakukan karena customer tidak mungkin mengingat semua portfolio perusahaan. Menurut Keller (2012), champion product adalah produk yang diingat pertama kali oleh customer ketika menyebut nama perusahaan. Jadi dapat disimpulkan champion products seperti duta besar yang merepresentasi perusahaan tersebut, Menurut Karjalainen (2010), desainer bila mengembangkan produk baru di kategori champion products harus lebih sensitif dengan nilai - nilai identitas visual maupun konsep yang ada di champion products. Berdasarkan pertimbangan penekanan biaya, meningkatkan variasi produk dalam waktu cepat, pengurangan waktu produksi, memudahkan quality control, maka perusahaan menerapkan strategi modularitas untuk konstruksi knock-down. Strategi ini adalah strategi R\&D dalam perusahaan dimana produk dibagi menjadi beberapa modul komponen yang membentuk fungsi produk, sehingga lini produk dapat dibuat variasinya dengan mudah, Sanchez (2002) dalam Andersson dan Warell (2015). 
Modul komponen dapat berupa komponen elektronik, komponen struktur dan material. Contohnya sebuah kursi memiliki 4 komponen (sandaran, kaki, dudukan, sandaran tangan), dimana masing - masing komponen ada variasi bentuk, material dan ukuran. Variasi desain produk dapat dibuat dengan kombinasi antara komponen - komponen ini. Keuntungan yang didapatkan dari konsep modularitas; penekanan biaya, meningkatkan variasi produk dalam waktu cepat, pengurangan waktu produksi, memudahkan quality control. Konsep awalnya juga adalah menggunakan modul standar ini sebagai referensi merancang furniture mid century versi knock-down.

Adapun 3 bagian modul pada konstruksi kursi knock-down di New Elegant Ltd. adalah seat frame, front legs dan chair back.

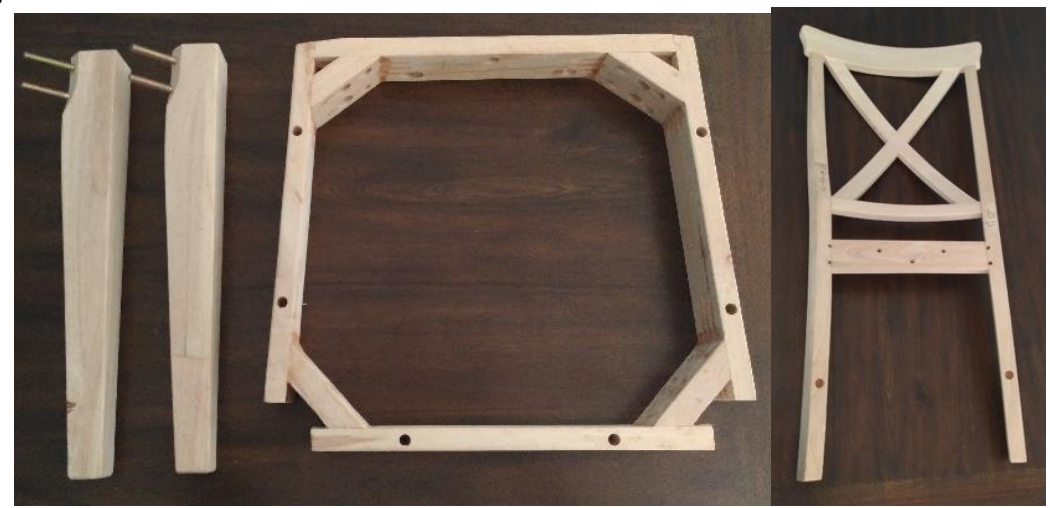

Gambar 1. front legs, seat frame, dan chair back standar kursi makan

Sumber: Data Pribadi, 2017

Perubahan pada ukuran kursi akan dilakukan terutama pada ukuran seat frame, yang kemudian akan diikuti oleh ukuran kaki dan chair back. Chair back seperti gambar diatas merupakan satu bagian yang akan dihubungkan pada seat frame. Gambar di bawah sebagai penjelas.

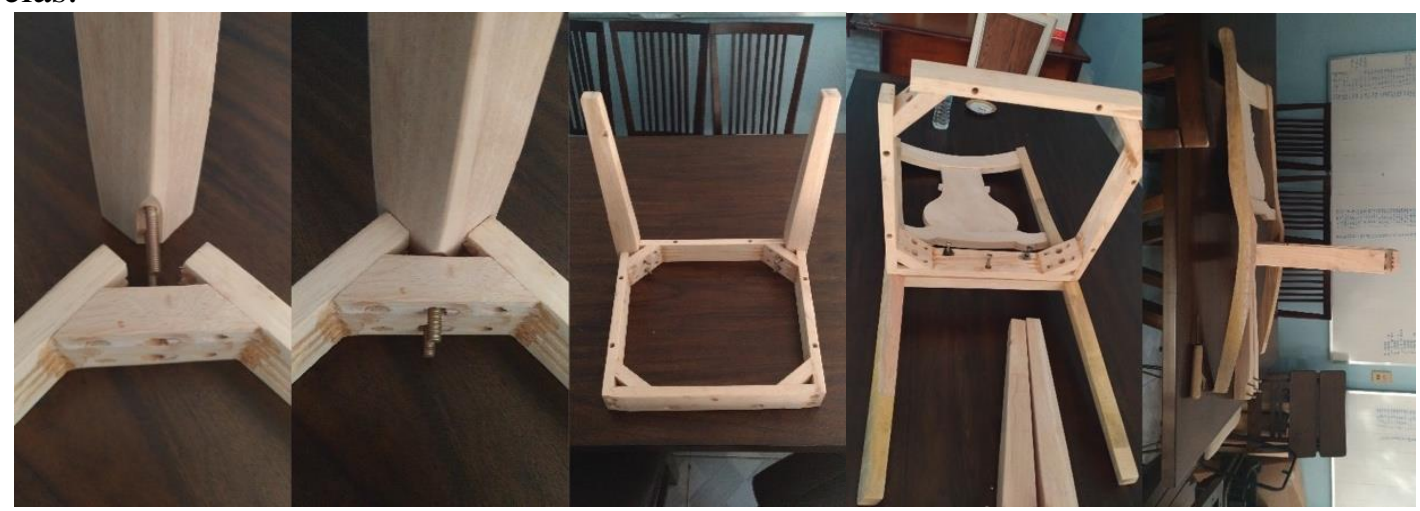

Gambar 2. Contoh pemasangan seat frame pada chair back Sumber: Data Pribadi, 2017

Pada chair back, terdapat satu bagian yang membedakan dengan kontruksi kursi mid century pada umumya. Bagian itu adalah bagian pada pertemuan antara back chair dengan seat frame. 


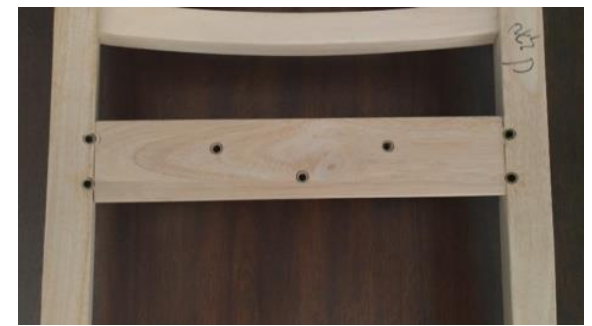

Gambar 3. Detail chair back

Sumber: Data Pribadi, 2017

Secara umum, konstruksi meja lebih sederhana dibanding kursi. Bentuk dan cara pasangnya bisa berbeda - beda menyesuaikan desain. Di bawah ini adalah beberapa gambar menjelaskan konstruksi meja yang ada pada umumnya.

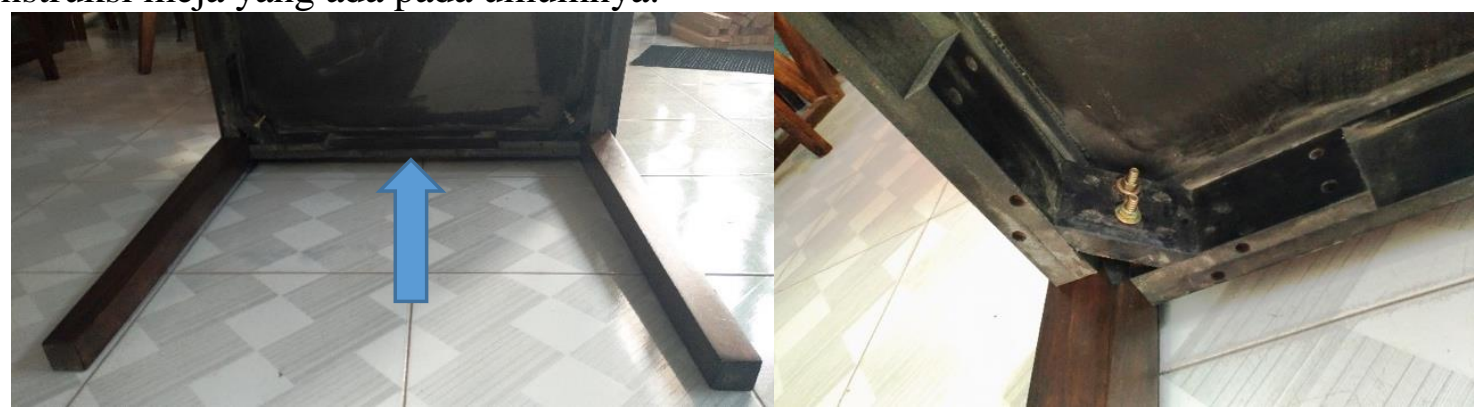

Gambar 4. Meja bagian bawah

Sumber: Data Pribadi, 2017

Seperti yang ada pada gambar di atas, bentuk konstruksi pemasangan kaki pada meja cukup mirip dengan yang ada pada kaki kursi bagian depan. Apron (tanda panah) adalah faktor kekuatan utama pada kaki - kaki meja. Tanpa apron kaki meja akan mudah bergoyang dan lepas. Apron juga berguna untuk menutupi konstruksi bagian dalam meja yang dapat mengurangi nilai estetika pada meja.

Ada juga bentuk meja dengan kaki yang tidak terpasang langsung pada apron. Jenis konstruksi ini membutuhkan dua lapis papan. Satu lapis akan tertempel pada table top bagian bawah, dan satu lainnya akan tertempel pada bagian kaki yang akan dilekatkan pada table top. Contohnya di bawah ini.

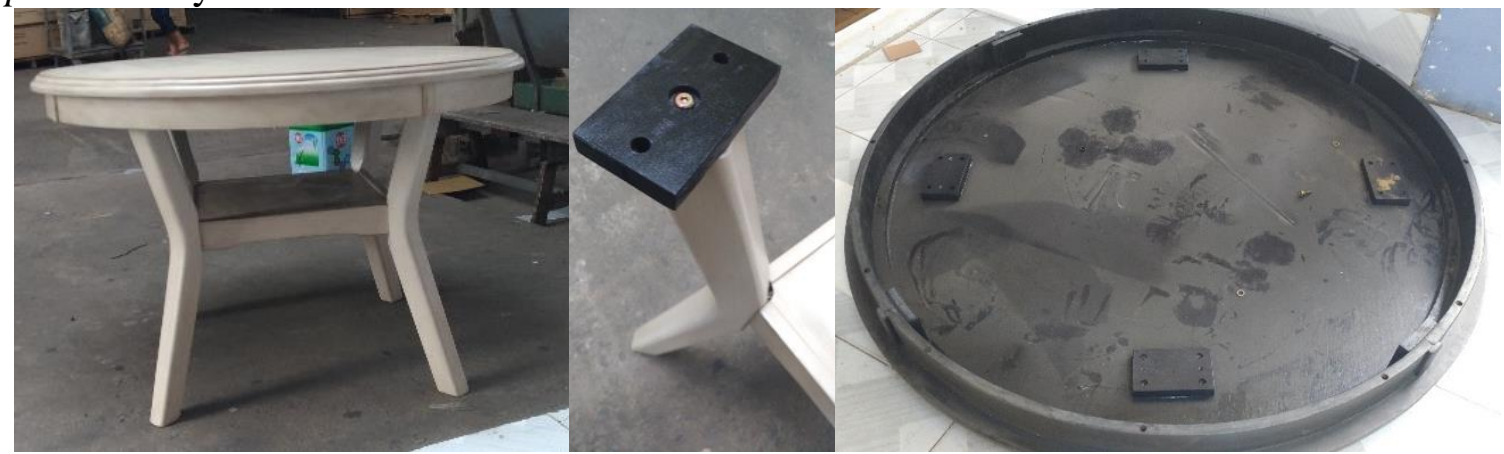

Gambar 5. Round dining table, struktur kaki, table top bagian bawah Sumber: Data Pribadi, 2017

Pada meja gambar 5, kaki - kaki meja yang tidak berbentuk lurus terdapat di dalam apron sehingga konstruksi menjadi sedikit berbeda. Sistem knock-down ini lebih kuat dibandingkan dengan pemasangan secara langsung menggunakan baut ke table top. 
Sistem knock-down kursi dan meja di atas telah terbukti kuat karena telah menghasilkan penjualan ribuan kontainer.

\subsubsection{Pengemasan (Packing)}

Dengan sistem tiga bagian utama (seat frame, front legs, dan chair back), proses packing dapat dilakukan dengan meng-horizontal-kan ketiga bagian tersebut. Dengan sistem ini, satu packaging dapat memuat 2 kursi.

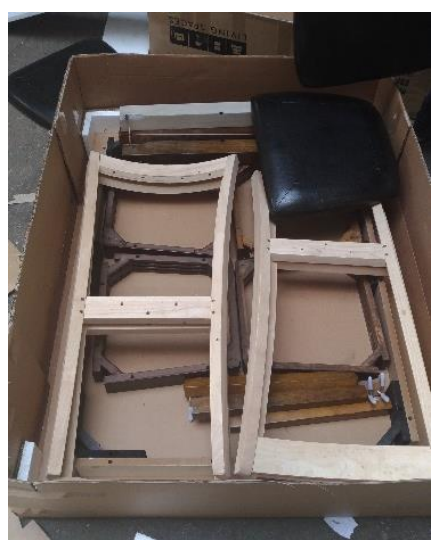

Gambar 6. Contoh packing 2 kursi/boks

Sumber: Data Pribadi, 2017

Ada pula packing untuk dining set (1 meja 4 kursi) seperti gambar diatas. Di situ terlihat ada 4 buah kursi yang tertata dengan 2 saling silang; tabletop dan kaki meja dibawahnya. Cara packing demikian dipakai untuk peritel yang menjual secara set, bukan satuan terpisah.

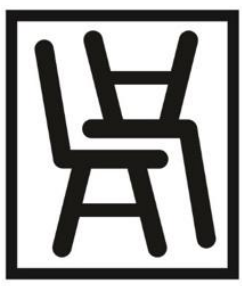

Gambar 7. Ilustrasi packaging kursi non-knock-down

Sumber: Data Pribadi, 2017

Ilustrasi di atas adalah cara umum packing 2 kursi siap pakai (non knock-down). Jelas bahwa volume yang terpakai lebih besar sehingga kuantitas dalam 1 kontainer akan lebih sedikit. Untuk ekspor impor, kontainer yang umum digunakan adalah $40 \mathrm{ft}$ High Cube dengan dimensi $12.035 \mathrm{~mm}$ panjang, $2.350 \mathrm{~mm}$ lebar dan $2.697 \mathrm{~mm}$ tinggi.

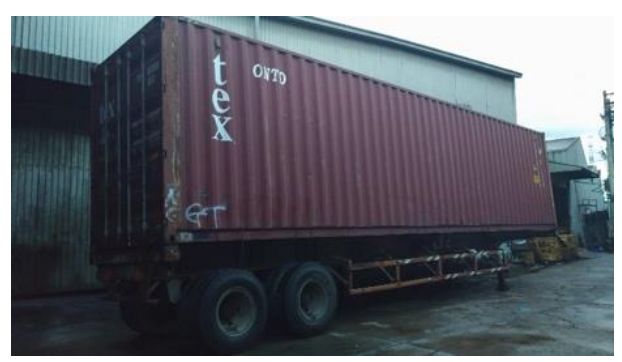

Gambar 8. kontainer 40ft hc

Sumber: Data Pribadi, 2017 

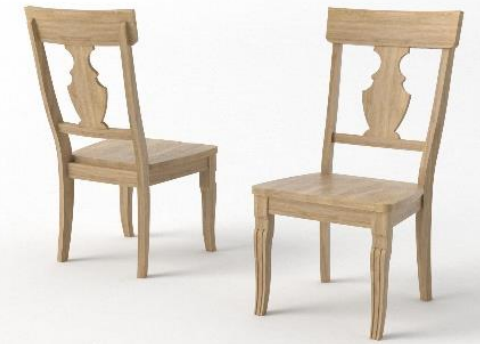

Gambar 9. D171214 Dining Chair

Sumber: dokumen pribadi, 2018

Sebagai contoh kasus kursi pada gambar 9, volume packaging untuk 2 buah kursi menggunakan sistim knock-down dalam 1 package adalah $17.16 \mathrm{~m}^{3}\left(6.06 \mathrm{ft}^{3}\right)$. Dengan volume ini, untuk 40ft high cube container mampu memuat 388 package. Sedangkan untuk jenis packaging assembled, volume yang terpakai untuk 1 package berisi 2 kursi adalah $45.16 \mathrm{~m} 3$ $\left(15.95 \mathrm{ft}^{3}\right)$. Dengan volume ini, container $40 \mathrm{ft} \mathrm{HC}$ hanya mampu memuat 147 package saja. Dengan contoh ini, jelas bahwa ada 241 package yang terbuang dalam 1 kali pengiriman jika tidak menggunakan sistem knock-down.

\subsubsection{Furnitur Mid Century}

Kursi mid century diatas diambil sebagai referensi desain. Beberapa mampu diproduksi karena memungkinkan untuk dibentuknya seat frame sebagai dasar utama konstruksi kursi. Beberapa lainnya tidak mampu untuk diproduksi karena ada beberapa faktor. Kursi Y karya Hans J. Wegner tidak bisa dibuat di pabrik rekanan karena memerlukan banyak tenaga kerja tangan (thread seat dan bentwood pada sandaran belakang). Referensi ini dipakai sebagai studi dan acuan untuk modifikasi desain.

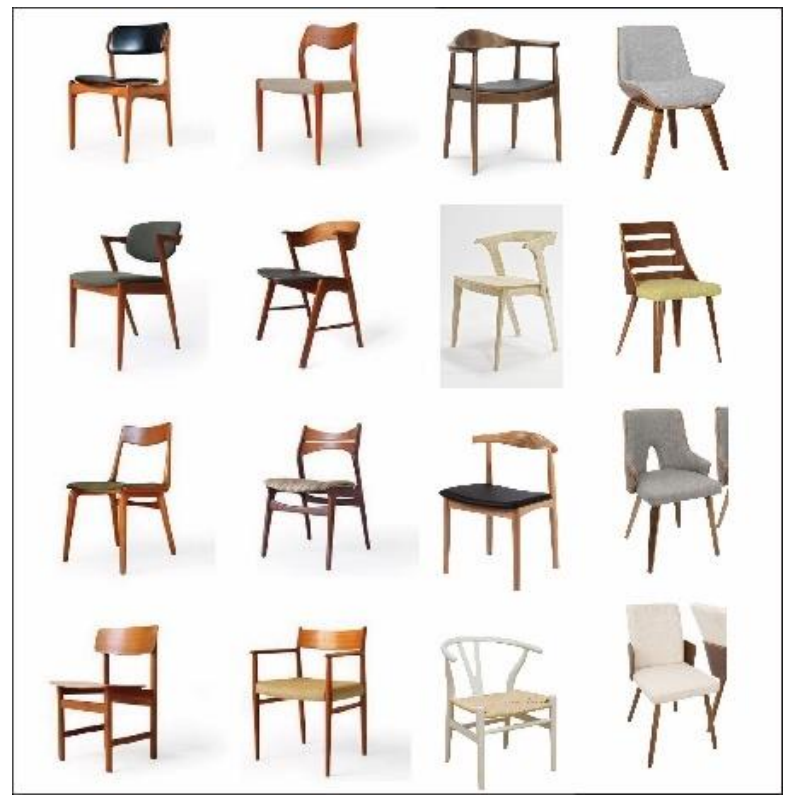

Gambar 6. Contoh kursi Mid Century

Sumber: Data Pribadi, 2017

Furnitur mid century terkenal rentan patah apabila dibuat knock-down karena gayanya yang ramping dengan material serba tipis dan kurus. Tidak semua kursi mid century juga cocok 
dibuat knock down karena penampilannya bisa berubah dan tidak lagi indah karena ada penambahan konstruksi. Untuk itu merupakan tantangan untuk merancang dining set mid century knock-down namun tetap kuat, estetis, dan bisa diproduksi oleh perusahaan.

\subsubsection{Studi Material}

Untuk material yang digunakan mayoritas adalah kayu akasia, kayu karet, plywood, dan MDF (Medium Density Fiberboard). Material - material ini sudah menjadi material utama untuk hampir seluruh produksi yang ada. Akan tetapi jika dibutuhkan material lain seperti metal, perusahaan akan memesan secara khusus dari perusahaan lain. Desain mid century yang diajukan juga mengikuti standar material perusahaan.

\section{1) Dining Chair}

Mayoritas dari material yang digunakan untuk kaki, seat frame, dan backrest pada kursi di New Elegant Ltd. adalah solid wood accacia dan rubber. Kedua kayu selalu digunakan sebagai material dasar pembuatan hampir seluruh furnitur yang ada dari perusahaan.

2) Seat

Jika desain seat yang dipilih merupakan hardwood, maka penggunaan materialnya juga menggunakan solid wood accacia atau rubber. Akan tetapi jika desain yang terpilih merupakan cushion seat, maka penggunaan materialnya merupakan plywood sebagai dasar seat, kemudian foam diatas plywood tersebut dan diselimuti fabric.

\section{3) Dining Table}

Untuk kaki - kaki meja dan apron pada umumnya menggunakan solid wood accacia atau rubber untuk kebutuhan kekuatan. Pada bagian table top, MDF (Medium Density Fibreboard) $17 \mathrm{~mm}$ merupakan material standar yang digunakan pabrik. Selain MDF, penggunaan veneer digunakan untuk memberikan kesan table top terbuat dari solid wood.

\subsubsection{Studi Warna}

Dari data penjualan, 2 warna ini merupakan yang terlaris (antique white dan burnt brown), sehingga untuk desain mid century akan menggunakan 2 warna ini dulu.

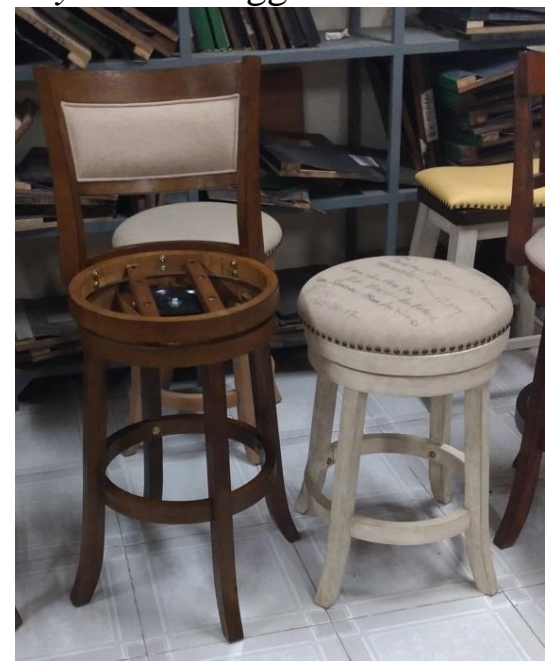

Gambar 7. 2 Warna Terlaris

Sumber: Data Pribadi, 2017

\section{Metode Penelitian}

\section{Alternatif Desain}




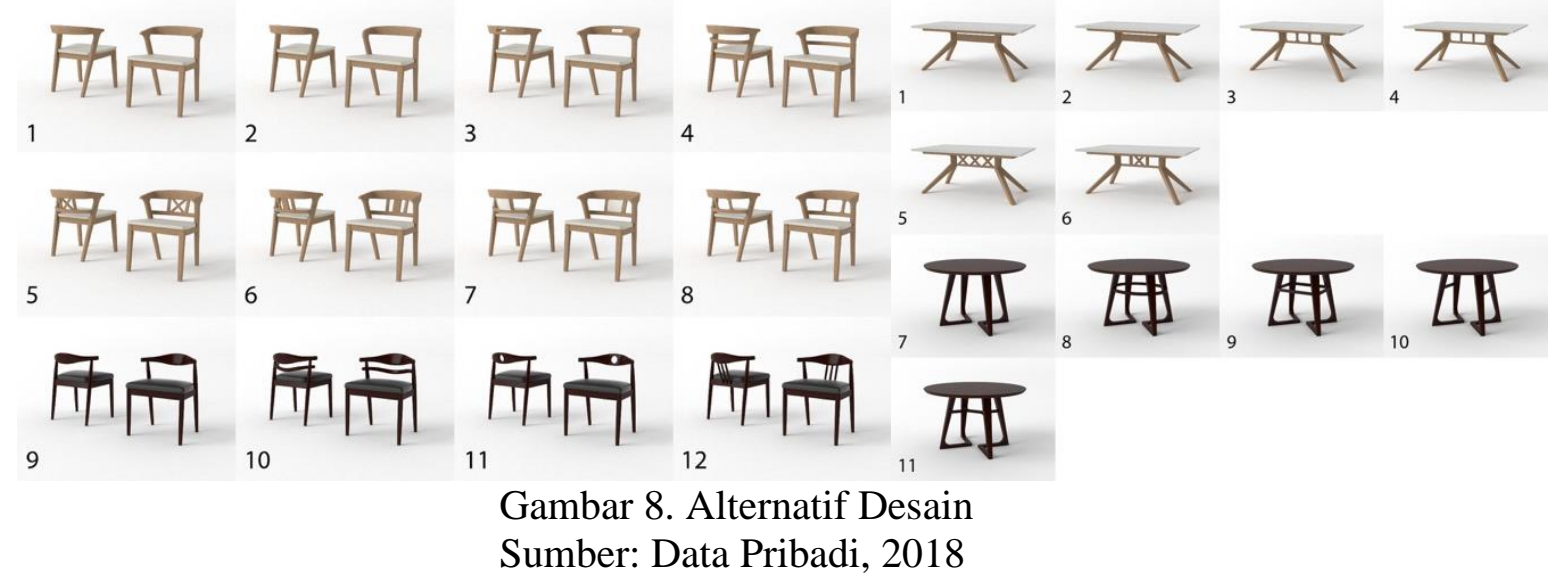

Alternatif desain kursi dibuat mengacu pada konstruksi kursi standar di New Elegant, Ltd. Hasilnya ada 12 desain, dan terpilih desain 5 dan 10 untuk dikembangkan lebih lanjut. Alternatif desain meja juga dibuat mengikuti konstruksi standar meja. Hasilnya ada 11 desain, dan terpilih desain 4 dan 11 untuk dikembangkan.

\section{Hasil/ Temuan}

\subsection{Desain Final}
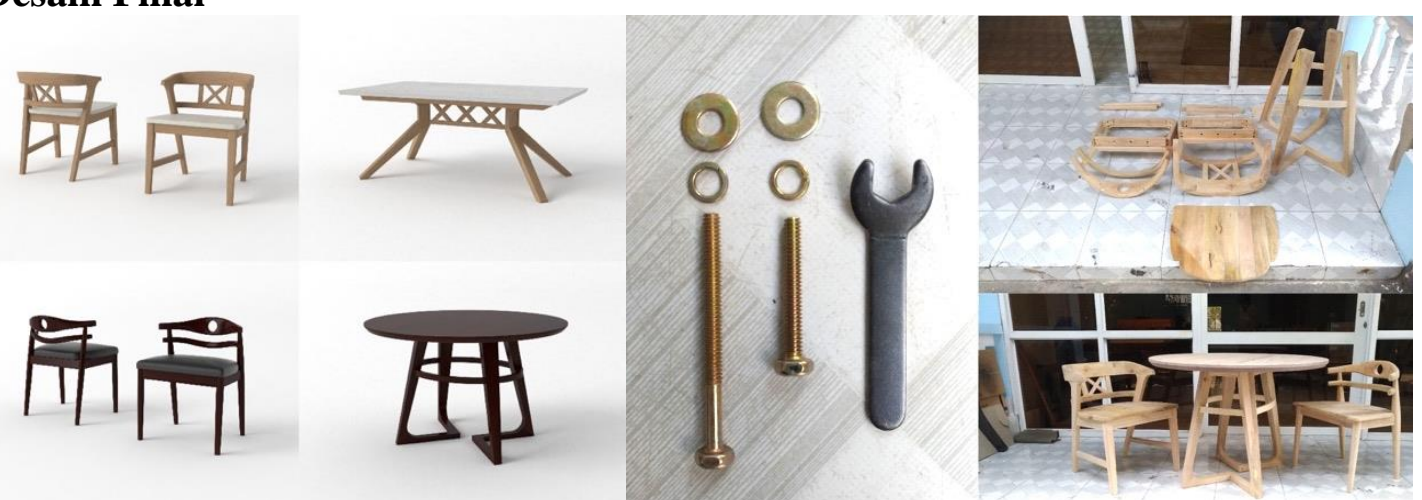

Gambar 9. Dining Set final

Sumber: Data Pribadi, 2018

Sistem konstruksi, fitting dan hardware yang digunakan adalah sistem konstruksi standar pabrik.

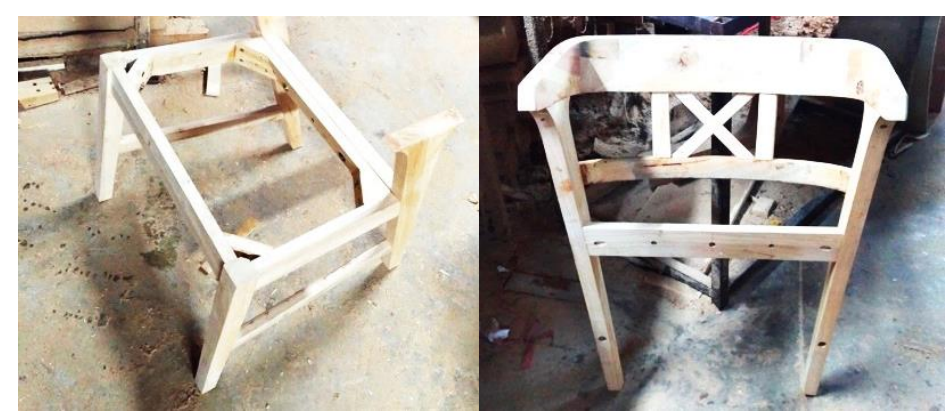




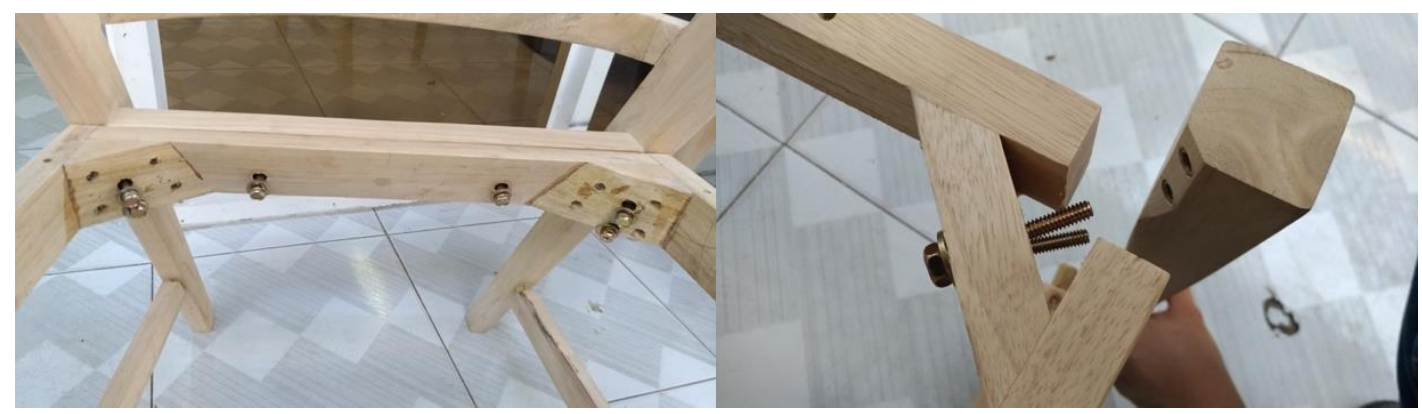

Gambar 10. Konstruksi Knock-down Kursi Desain Final

Sumber: Data Pribadi, 2017

Dengan menggunakan 2 baut pada kedua ujung seat frame yang ditambah 2 baut lagi pada bagian tengah papan seat frame, back rest akan mampu melekat kuat tanpa ada goyang. Penggunaan 2 baut itu juga dilakukan pada front leg, dengan ini front leg tidak akan goyang atau lepas dibandingkan dengan 1 baut.

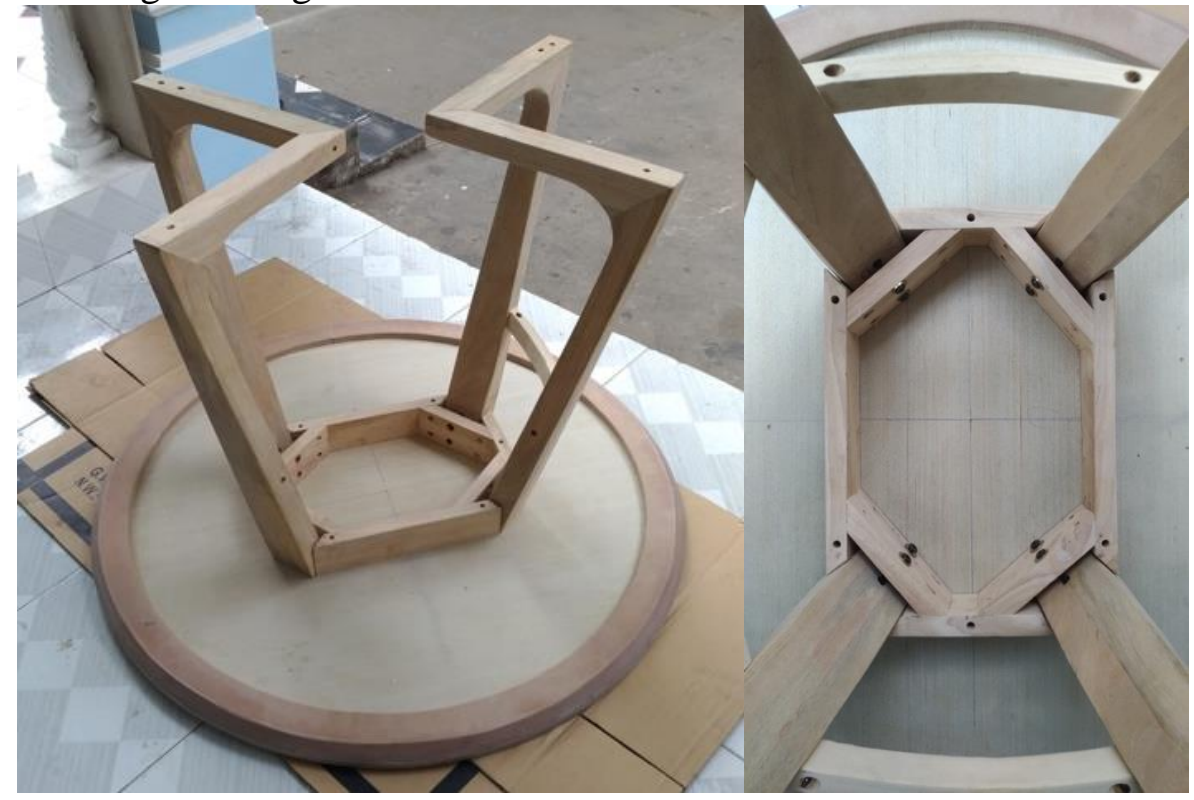

Gambar 11. Konstruksi Knock-down Meja Desain Final

Sumber: Data Pribadi, 2017

Konstruksi meja juga tidak berbeda jauh dengan konstruksi kursi. Kaki dilekatkan menggunakan 2 baut pada apron. Hal ini juga memastikan kekuatan kaki yang tidak akan goyang atau lepas. Stretcher menggunaakan sistem mortise and tenon yang kemudian akan dilekatkan menggunakan screw melalui sisi bawah untuk memperkuat konstruksi.

\subsection{Biaya Produksi}

Target market New Elegant, Ltd. adalah masyarakat kelas menengah dengan harga satuan yang ditawarkan ke klien berkisar antara USD30-33. Peritel biasanya akan menjual harga 3x lipat dari harga penawaran.

Tabel 1. Studi Biaya Meja

\begin{tabular}{|l|l|c|c|c|r|}
\hline No. & Material per part/ Hardware & Ukuran mm & Jumlah & Harga USD & Total Harga USD \\
\hline 1 & MDF Veneer New Zealand & $1065 \times 1065 \times 17$ & 1 & $900 / \mathrm{m} 3$ & 17.4 \\
\hline 2 & MDF & $550 \times 70 \times 17$ & 6 & $900 / \mathrm{m} 3$ & 3.53 \\
\hline 3 & Rubber Wood & $330 \times 70 \times 25$ & 2 & $900 / \mathrm{m} 3$ & 1.04 \\
\hline
\end{tabular}




\begin{tabular}{|l|l|l|c|r|r|}
\hline 4 & Rubber Wood & $190 \times 70 \times 25$ & 2 & $900 / \mathrm{m} 3$ & 0.60 \\
\hline 5 & Rubber Wood & $160 \times 70 \times 20$ & 4 & $900 / \mathrm{m} 3$ & 0.81 \\
\hline 6 & Rubber Wood & $750 \times 85 \times 50$ & 4 & $900 / \mathrm{m} 3$ & 11.48 \\
\hline 7 & Rubber Wood & $365 \times 45 \times 70$ & 4 & $900 / \mathrm{m} 3$ & 4.14 \\
\hline 8 & Plywood & $425 \times 35 \times 20$ & 2 & $900 / \mathrm{m} 3$ & 0.54 \\
\hline 9 & Plywood & $275 \times 35 \times 20$ & 2 & $900 / \mathrm{m} 3$ & 0.35 \\
\hline 10 & Vis & $4 \times 38$ & 6 & 0.0031 & 0.0185 \\
\hline 11 & Vis & $4 \times 30$ & 8 & 0.0025 & 0.0198 \\
\hline 12 & Vis & $4 \times 35$ & 8 & 0.0028 & 0.0226 \\
\hline 13 & Vis & $4 \times 25$ & 16 & 0.0020 & 0.0325 \\
\hline 14 & Flat Washers dia & $5 / 16 " \times 63$ & 8 & 0.0301 & 0.2406 \\
\hline 15 & Spring Washers & $5 / 16 "$ & 8 & 0.0045 & 0.0381 \\
\hline 16 & Flat Washers & $5 / 16 "$ & 8 & 0.0033 & 0.0265 \\
\hline 17 & Allen Wrench & $5 / 16 "$ & 1 & 0.0384 & 0.0384 \\
\hline 18 & Snail & $5 / 16 " \times 20$ & 8 & 0.0137 & 0.1094 \\
\hline
\end{tabular}

Sumber: Dokumen pribadi, 2018

Dengan metode hitung yang sama, biaya untuk kursi 1 dan 2 adalah USD23.877 dan USD20.859. Harga-harga ini tentunya masih masuk dalam kisaran harga yang cocok untuk target market perusahaan.

Untuk kursi 1, berikut perbandingan efisiensi untuk standar pengemasan 2 kursi per boks. Hasilnya kuantitas knock-down bisa menampung $48 \%$ lebih banyak dari yang non knock-down.

Tabel 1. Daya Tampung Kontainer Desain Final

\begin{tabular}{|l|c|c|}
\hline \multicolumn{1}{|c|}{ Parameter } & Non Knock-down & Knock-down \\
\hline Volume & $24 \times 25 \times 48$ ” & $24 \times 16 \times 39 ”$ \\
\hline Kuantitas per kontainer 40ft HC & 141 boks & 271 boks \\
\hline
\end{tabular}

Sumber: Dokumen pribadi, 2018

Kursi 2 dan meja tentunya akan menghasilkan perhitungan yang lebih efisien juga.

\section{Kesimpulan}

Desain kursi mid century knock-down yang bisa diproduksi New Elegant Ltd., adalah yang memiliki 3 konstruksi dasar sama dengan standar pabrik (seat frame, front legs, chair back). Sedangkan untuk desain meja mid century yang bisa diproduksi adalah yang memiliki struktur table top dan table legs yang dikunci dengan hardware (baik dengan atau tanpa apron). Bentuk desain sifatnya relatif, menyesuaikan ciri-ciri desain mid century yang membulat dan ramping. Harga penawaran ke klien harus yang masuk dalam kisaran harga ritel USD90-99 per produk, dan sesuai perhitungan biaya, desain masuk dalam kategori harga yang kompetitif. Secara loadability pun, daya tampung dalam 1 kontainer 40ft HC lebih besar 48\% dibanding set serupa yang tidak knock-down. Dengan demikian, model desain ini bisa menjadi salah satu referensi bagaimana cara modifikasi desain mid century versi knock-down.

\section{Daftar Pustaka}

[1] Data New Elegant, Ltd. 
[2] J.N. Kapferer, The new strategic Brand Management: Advanced insights \& strategic Thinking, fifth ed. 2014

[3] K.L. Keller, T. Apéria \& M. Georgson, Strategic Brand Management: a European perspective, second ed. 2012.

[4] Andersson Torbjorn, Warrel Anderson, Aesthetic flexibility in the management of visual product branding.6th International Conference on Applied Human Factors and Ergonomics (AHFE 2015) and the.

\section{Penghargaan}

Terima kasih kepada para stakeholder New Elegant, Ltd. yang mau terbuka memberikan data dan informasi yang dibutuhkan dengan lengkap dan transparan. Harapannya adalah agar data ini bisa berguna untuk kebutuhan akademis. Mudah-mudahan studi kasus ini bisa membantu. 